\title{
How common is chronic fatigue syndrome; how long is a piece of string? Peter D White*
}

\author{
Address: Centre for Psychiatry, Wolfson Institute of Preventive Medicine, Barts and the London, Queen Mary School of Medicine and Dentistry, \\ London, EC1A 7BE, UK \\ Email: Peter D White* - p.d.white@qmul.ac.uk \\ * Corresponding author
}

Published: 8 June 2007

Population Health Metrics 2007, 5:6 doi:10.1 186/1478-7954-5-6

This article is available from: http://www.pophealthmetrics.com/content/5/l/6

(c) 2007 White; licensee BioMed Central Ltd.

This is an Open Access article distributed under the terms of the Creative Commons Attribution License (http://creativecommons.org/licenses/by/2.0), which permits unrestricted use, distribution, and reproduction in any medium, provided the original work is properly cited.
Received: 8 May 2007

Accepted: 8 June 2007

\author{
Abstract \\ Commentary on \\ Prevalence of chronic fatigue syndrome in metropolitan, urban, and rural Georgia \\ William C Reeves, James F Jones, Elizabeth Maloney, Christine Heim, David C Hoaglin, Roumiana \\ S Boneva, Marjorie Morrissey and Rebecca Devlin
}

One of the most difficult tasks in medicine is to accurately measure how common illnesses are. Why do we do it? Justifications include being able to plan health care and public health priorities, as well as highlighting specific diseases for extra funding for both health care and research. Yet the jobbing physician at the sharp edge of clinical practice cares little about the exact prevalence of a disease or illness, since this is all too obvious from the frequency of the problems presented by patients who come through the door.

\section{How do you measure a syndrome?}

If the disease in question has no biological marker and is difficult to define clinically, the problem of working out the accurate prevalence becomes esoteric. Chronic fatigue syndrome (CFS) is just such an illness. It has as many synonyms as putative causes, being also called myalgic encephalomyelitis, chronic immune dysfunction syndrome, and post-viral fatigue syndrome, amongst others. Since fatigue is one of the most common symptoms reported by patients in general, delineating a specific syndrome with fatigue as a central feature risks arbitrary decisions about ascertainment. Do we categorise the syndrome on the basis of the severity of fatigue, the number of associated symptoms, or the severity of the resultant disability? Even measuring the consequent disability gives us problems since there are only weak correlations between subjective and objective observations [1]. It is therefore no great surprise that half of all doctors do not even believe it exists [2].

And yet, patients and their organisations constantly criticize doctors both for not believing in the existence of CFS and for not taking patients seriously. Even politicians seem to take the problem more seriously than some doctors do. This may be as much to do with successful lobbying as the economic costs of CFS, which have been estimated as $\$ 9$ billion per annum just for lost productivity in the USA [3]. Doctors don't understand things they can't see or measure, and patients mistrust doctors who don't understand them. We are in a conundrum.

\section{One way forward}

The Centers for Disease Control and Prevention (CDC) in the United States of America are one of the few health care agencies who do take CFS seriously, to the extent of sup- 
porting a $\$ 4$ million public education campaign, which started last year [4]. They have also led the way in providing operationalised criteria in order to standardize the diagnosis of CFS [5]. Their latest research programme has been based on a large survey of the adult (18-59 years old) population of the state of Georgia, USA, in order to better understand the epidemiology and etiology of CFS [6]. Their previous study of prevalence, in Wichita, Kansas, suggested a prevalence of $0.24 \%$ [7]. Another independent population survey in Chicago suggested a prevalence of $0.42 \%$ [8]. The CDC has now repeated and extended the Wichita study in Georgia, and found a prevalence of between six and ten times greater, with $2.5 \%$ of the population suffering from CFS [6]. If this prevalence was both accurate and representative of the USA as a whole, this would suggest that some 7.5 million Americans were sufferers, compared to the previous estimates of 0.7 to 1.2 million.

\section{A cautious interpretation}

Could this really be true? The authors are sensibly cautious in their interpretations, and point out the uncertainties inherent within the study. There are three main reasons why we should be cautious about interpretation and generalizing from this finding. Compared to previous studies, there were important differences in the method of ascertainment used in the Georgia study that may help to explain the greater prevalence. Most importantly, the Georgia study used a different initial screening question. Instead of asking whether a household member was suffering from "fatigue", as previously done, the screening question asked about being "unwell", by which was meant having one or more of the following symptoms for a month or more: "fatigue, cognitive impairment, unrefreshing sleep, muscle pain, joint pain, sore throat, tender lymph nodes, or headache" (all being likely symptoms of CFS). The authors suggested that this stratagem picked up an extra $11.5 \%$ of CFS cases. A strength of the Georgia survey was the use of standardised measures of symptoms and disability. However in order to count someone as fatigued - the central criterion for a diagnosis of CFS individuals only needed to score the median or more of the well population, either for fatigue or inactivity. In a previous study, the same authors found that using such standardised measures picked up three times as many cases of CFS than verbatim enquiries [9]. These methodological differences mean it is not possible to directly compare the prevalence of CFS in Georgia with previous studies.

Comorbid psychiatric conditions may have inflated the prevalence. A previous study found an equally high point prevalence of CFS (2.6\%), by surveying United Kingdom primary care patients [10]. However, when those patients who also had a comorbid psychiatric disorder were excluded, the prevalence fell to $0.5 \%$. Although it will be important to publish the prevalence of comorbid psychiatric disorders in the Georgian survey, the argument can still be put that these comorbid psychiatric disorders were secondary to having chronic ill-health, rather than the primary and explanatory condition. The current design cannot determine the direction of causality, although previous longitudinal studies suggest that psychiatric ill health can both follow and precede CFS [11,12].

Georgia may not be representative of the USA as a whole. For instance, we do not know the body mass index (BMI) of the Georgian sample. The Wichita sample of CFS cases contained $43 \%$ of subjects with a BMI of 30 or over, representing significant obesity [9]. This compares with $20 \%$ in the USA as a whole [13]. Since obesity is associated with fatigue [14], a similar proportion in Georgia might inflate the prevalence of CFS.

\section{To conclude}

What can we conclude from this very large survey? Although methodological issues may help to explain the high prevalence of CFS found in this study, the argument can still be made that the prevalence of CFS is greater than previously thought $[10,15]$. CFS is at least as common in ethnic minorities in the USA as in the ethnic Caucasian majority; a welcome replication of previous studies [8]. CFS is not an exclusively white syndrome. Social issues may help to explain why women suffer CFS more than men. But perhaps the most important conclusion is that there were about twice as many people in Georgia who were unwell with fatigue, who did not meet the criteria for CFS. Our current criteria for diagnosing CFS are arbitrary [16], and we need to widen the net to capture all those people who become so chronically tired and unwell that they can't live their lives to their full potential. The jobbing physician does not close the door on those who don't meet criteria.

\section{Conflict of interest}

Professor White has collaborated with some of the authors in research into CFS.

\section{References}

I. Afari N, Buchwald D: Chronic fatigue syndrome: a review. $\mathrm{Am} J$ Psychiatry 2003, 160:221-236.

2. Thomas MA, Smith AP: Primary healthcare provision and chronic fatigue syndrome: a survey of patients' and General Practitioners' beliefs. BMC Fam Pract 2005, 6:49.

3. Reynolds KJ, Vernon SD, Bouchery E, Reeves WC: The economic impact of chronic fatigue syndrome. Cost Effectiveness Resource Allocation 2004, 2:4.

4. Centers for Disease Control and Prevention: Chronic Fatigue Syndrome. 2006 [http://www.cdc.gov/cfs/awareness.htm].

5. Reeves WC, Lloyd A, Vernon SD, Klimas N, Jason LA, Bleijenberg G, Evengard B, White PD, Nisenbaum R, Unger ER: Identification of ambiguities in the 1994 chronic fatigue syndrome research case definition and recommendations for resolution. BMC Health Services Research 2003, 3:25. 
6. Reeves WC, Jones JF, Maloney E, Heim C, Hoaglin DC, Boneval RS, Morrissey M, Devlin R: Prevalence of chronic fatigue syndrome in metropolitan, urban, and rural Georgia. Population Metrics . (this issue)

7. Reyes M, Nisenbaum R, Hoaglin DC, Unger ER, Emmons C, Randall B, Stewart JA, Abbey S, Jones JF, Gantz N, Minden S, Reeves WC: Prevalence and incidence of chronic fatigue syndrome in Wichita, Kansas. Arch Int Med 2003, 163:1530-1536.

8. Jason LA, Richman JA, Rademaker AW, Jordan KM, Plioplys AV, Taylor RR, McCready W, Huang CF, Plioplys S: A community-based study of chronic fatigue syndrome. Arch Int Med 1999, 159:2129-2137.

9. Reeves WC, Wagner D, Nisenbaum R, Jones JF, Gurbaxani B, Solomon L, Papanicolaou DA, Unger ER, Vernon SD, Heim C: Chronic fatigue syndrome - A clinically empirical approach to its definition and study. BMC Medicine 2005, 3:19.

10. Wessely S, Chalder T, Hirsch S, Wallace P, Wright D: The prevalence and morbidity of chronic fatigue and chronic fatigue syndrome: a prospective primary care study. Am J Public Health 1997, 87: | 449-| 455

II. Hickie I, Koschera A, Hadzi-Pavlovic D, Bennett B, Lloyd A: The temporal stability and co-morbidity of prolonged fatigue: $A$ longitudinal study in primary care. Psychol Med 1999, 29:855-861.

12. van der Linden G, Chalder T, Hickie I, Koschera A, Sham P, Wessely S: Fatigue and psychiatric disorder: different or the same? Psychol Med 1999, 29:863-868.

13. Mokdad AH, Bowman BA, Ford ES, Vinicor F, Marks JS, Koplan SJ: The continuing epidemics of obesity and diabetes in the United States. JAMA 200I, 286: I 195-I 200.

14. Lim W, Hong S, Nelesen R, Dimsdale JE: The association of obesity, cytokine levels, and depressive symptoms with diverse measures of fatigue in healthy subjects. Arch Intern Med 2005, 165:910-915.

15. Evengård Ba, Jacks A, Pedersen NL, Sullivan PF: The epidemiology of chronic fatigue in the Swedish twin registry. Psychol Med 2005, 35: I 327-I336.

16. Sullivan PF, Pedersen NL, Jacks A, Evengå B: Chronic fatigue in a population sample: definitions and heterogeneity. Psychol Med 2005, 35: $1337-1348$

Publish with Bio Med Central and every scientist can read your work free of charge

"BioMed Central will be the most significant development for disseminating the results of biomedical research in our lifetime. "

Sir Paul Nurse, Cancer Research UK

Your research papers will be:

- available free of charge to the entire biomedical community

- peer reviewed and published immediately upon acceptance

- cited in PubMed and archived on PubMed Central

- yours - you keep the copyright 